\title{
HUBUNGAN KEJADIAN KARIES GIGI DENGAN KONSUMSI MAKANAN KARIOGENIK DAN STATUS GIZI PADA ANAK SEKOLAH DASAR (Studi Pada Anak Kelas III dan IV SDN Kadipaten I dan II Bojonegoro)
}

\author{
Hana Yuwan Kartikasari, Nuryanto ${ }^{*}$ \\ Program Studi Ilmu Gizi Fakultas Kedokteran Universitas Diponegoro \\ Jl.Dr.Sutomo No.18, Semarang, Telp (024) 8453708, Email : gizifk@undip.ac.id
}

\begin{abstract}
Background : Elementary school students in the region Kabupaten Bojonegoro amounted to $77.4 \%$ suffer dental caries. These conditions relate to the habit of cariogenic foods that contain sugar, sweet and sticky on the surface of the tooth. It can increase the risk of dental caries. Children who experience dental caries function is impaired, so it will affect the nutrient intake and nutritional status. This study aims to determine the relationship of cariogenic food consumption and dental caries incidence with nutritional status for children class 3 and 4 SDN Kadipaten 1 and II in Bojonegoro.

Methods : This study used a cross sectional design. The study population were all students in class 3 and 4 SDN Kadipaten 1 and II in Bojonegoro for academic year 2013/2014 amount 345 children. 63 Children were taken by simple random sampling technique. The independent variable in this study is the consumption of cariogenic foods and the dependent variable was dental caries and nutritional status. The primary data obtained through interviews and research questionnaire and secondary data obtained through measurement of height and weight. Data analysis use the Spearman rank correlation test.

Results : The results shows 46 children (73\%) having cariogenic foods 3-6x a day. The frequency of dental caries in the medium category, namely the DMF-T index average of 4.0. Most of the students (48.0\%) had fat nutritional status. Correlation test results shows $t: 1)$ there is a relationship between the cariogenic consumption foods with dental caries ( $p=0.000 ; r=-0547)$, 2) there is a relationship between dental caries and nutritional status ( $p=$ $0.057 ; r=-0202)$.

Conclusion : Based on the research concluded that there is a relationship between cariogenic consumption foods with dental caries incidence in children of class III and IV SDN I and II Kadipaten Bojonegoro. The incidence of dental caries children of class III and IV also there is a relationship with the child's nutritional status.

Keywords : Cariogenic Food, Dental Caries, Nutritional Status
\end{abstract}

\begin{abstract}
ABSTRAK
Latar Belakang : Karies gigi merupakan salah satu masalah kesehatan gigi dan mulut yang sering dijumpai di masyarakat, dimana diantaranya adalah golongan anak. Mengkonsumsi makanan kariogenik berlebih dapat meningkatkan risiko karies gigi. Anak yang mengalami karies gigi dalam kurun waktu yang lama akan berpengaruh terhadap asupan zat gizi dan status gizi. Penelitian ini bertujuan untuk mengetahui hubungan kejadian karies gigi dengan konsumsi makanan kariogenik dan status gizi pada anak sekolah dasar

Metode : Penelitian ini menggunakan rancangan cross sectional. Besar subjek yang dibutuhkan sebanyak 63 responden. Subjek diambil secara random sampling. Data yang dikumpulkan meliputi tingkat karies gigi menggunakan indeks DMF-T, asupan makanan kariogenik diperoleh menggunakan Food Frekuensi Question (FFQ) dan kuesioner, dan status gizi dengan cara antropometri. Analisis data menggunakan uji korelasi rank Spearman.

Hasil : Hasil penelitian menunjukkan tingkat karies gigi sedang 23.8\% dengan indeks DMF-T rata-rata 4.0 . Frekuensi konsumsi makanan kariogenik sebanyak 73\% mengkonsumsi 3-6x sehari. Terdapat 15.8\% anak memiliki status gizi sangat kurang. Hasil uji korelasi menunjukkan bahwa: ada hubungan antara kejadian karies gigi dengan konsumsi makanan karieogenik $(p=0.009 ; r=0.298)$, ada hubungan antara karies gigi dengan status gizi $(p=0.008$ ; $r=0.303$ ).
\end{abstract}

Simpulan : Berdasarkan penelitian disimpulkan bahwa ada hubungan antara kejadian karies gigi dengan konsumsi makanan karieogenik, dan ada hubungan antara karies gigi dengan status gizi

Kata Kunci : Makanan Kariogenik, Karies Gigi, Status Gizi

\section{PENDAHULUAN}

Usia sekolah, merupakan salah satu tahapan kehidupan yang masih mengalami pertumbuhan. ${ }^{1}$ Usia tersebut aktifitas fisik meningkat, seperti bermain dan berolahraga, sehingga dibutuhkan asupan gizi yang tinggi agar kecukupan zat gizi dapat terpenuhi. Tumbuh kembang pada anak sekolah tergantung pada

\footnotetext{
${ }^{*}$ Penulis Penanggungjawab
} 
pemberian asupan zat gizi dengan kualitas dan kuantitas yang baik. Kebiasaan makan pada anak sekolah sangat berpengaruh terhadap asupan zat gizinya. Kebiasaan makan yang salah pada anak sekolah dasar (SD) sering terjadi, seperti kebisaan mengkonsumsi makanan jajanan secara berlebihan. Makanan jajanan yang sering dikonsumsi anak SD banyak bersifat kariogenik, seperti makanan manis, lengket, dan makanan yang berbentuk menarik. Efek buruk dari seringnya mengkonsumsi makanan manis atau kariogenik yaitu terhadap kesehatan gigi. Hal ini disebabkan karena makanan kariogenik mempunyai kecenderungan melekat pada permukaan gigi. Bila hal ini sering terjadi maka dapat menyebabkan karies gigi. ${ }^{2}$

Berdasarkan penelitian yang dilakukan pada anak SD di Panei Tongah pada tahun 2009, menunjukkan bahwa makanan manis yang berbentuk lunak dan lengket dapat berpengaruh langsung terhadap terjadinya penyakit karies gigi. Mengkonsumsi makanan yang mengandung gula tinggi, seperti coklat, permen, roti isi, bakso, serta biskuit mempunyai korelasi tinggi dengan kejadian karies gigi. Konsumsi makanan kariogenik yang sering dan berulang-ulang akan menyebabkan $\mathrm{pH}$ plak dibawah normal dan menyebabkan demineralisasi enamel dan terjadilah pembentukan karies gigi. ${ }^{3}$

Anak yang mengalami karies gigi fungsi pengunyahannya akan terganggu, sehingga akan berpengaruh terhadap asupan zat gizi dan status gizinya. Hasil penelitian anak anak SDN (Sekolah Dasar Negeri) di desa Pagersari Kabupaten Kendal tahun 2004, didapatkan hasil bahwa ada hubungan karies gigi dengan status gizi anak sekolah dasar. Penelitian tersebut menjelaskan bahwa akibat dari karies gigi karena terganggunya fungsi pengunyahan (mastikasi) yang dapat berpengaruh terhadap asupan makanan. ${ }^{4}$

Survei Departemen Kesehatan Republik Indonesia tahun 2010 menunjukkan prevalensi penduduk Indonesia yang menderita karies gigi sebesar 80\% - 90\% dimana diantaranya adalah golongan anak. Hasil Riset Kesehatan Dasar tahun 2013 sebesar 30\% penduduk Indonesia mempunyai masalah gigi dan mulut. Jawa Timur adalah salah satu provinsi yang mempunyai masalah gigi dan mulut cukup tinggi $(>30 \%) .^{5}$ Kabupaten Bojonegoro merupakan salah satu kabupaten di Jawa Timur, dari total 116.095 siswa SD/MI yang memeriksakan gigi dan mulut, kejadian karies gigi sebesar 77,4\%. Hasil laporan pemeriksaan gigi yang didapatkan di SDN Kadipaten I dan II Kabupaten Bojonegoro cukup tinggi dengan kejadian karies giginya, yaitu $65 \%$ siswa kelas 3 dan 4 menderita karies gigi. ${ }^{6}$

Berdasarkan paparan tersebut, rumusan masalahnya adalah bagaimana hubungan konsumsi makanan kariogenik dengan kejadian karies gigi dan status gizi pada anak SDN Kadipaten I dan II Kabupaten Bojonegoro. Tujuan penelitian ini adalah untuk mengetahui hubungan konsumsi makanan kariogenik dengan kejadian karies gigi dan status gizi pada anak SDN Kadipaten I dan II Bojonegoro.

\section{METODE PENELITIAN}

Penelitian dilaksanakan pada bulan November 2013 di SDN Kadipaten I dan II Bojonegoro. Penelitian ini menggunakan rancangan cross sectional dengan melakukan pengukuran dan pengamatan variabel bebas maupun variabel terikat pada saat bersamaan. Besar subjek yang dibutuhkan dalam penelitian ini sebanyak 63 responden. Subjek diambil secara random sampling.

Data yang dikumpulkan meliputi identitas subjek, karies gigi, status gizi, dan konsumsi makanan kariogenik. Karies gigi merupakan keadaan kerusakan jaringan gigi yang dilihat dari tingkat/ indeks karies gigi (DMF-T) yang dilakukan oleh dokter gigi. Status gizi ditentukan berdasarkan pengukuran (BB/TB) dengan menggunakan Body Mass Index (BMI) yang dikonversikan ke dalam nilai z-score IMT/U untuk anak laki-laki dan perempuan 5-18 tahun menggunakan program WHO Anthro Plus 2007. Berat badan ditimbang dengan timbangan digital yang memiliki kapasitas $150 \mathrm{~kg}$ dan ketelitian 0.1 $\mathrm{kg}$, sedangkan tinggi badan diukur dengan microtoise dengan ketelitian $0.1 \mathrm{~cm}$. Makanan kariogenik merupakan frekuensi makanan yang bersifat kariogenik yang dikonsumsi oleh anak SD yang didapatkan dari Food Frekuensi Question (FFQ). Frekuensi makanan kariogenik yang dikonsumsi subjek termasuk kategori tinggi jika mengkonsumsi 3-6x atau lebih dalam sehari, kategori sedang $2 \mathrm{x}$ dalam sehari dan kategori rendah $1 \mathrm{x}$ dalam sehari.

Analisis data untuk mengetahui hubungan antara konsumsi makanan kariogenik dengan kejadian karies gigi dan status gizi menggunakan uji Korelasi Spearman yang sebelumnya diuji normalitas datanya dengan uji KolmogorovSmirnov. 
HASIL PENELITIAN

A. Karakteristik Responden
Responden penelitian sebanyak 63 anak SD kelas 3 dan 4 dengan karakteristik responden dapat dilihat pada tabel 1 .

Tabel 1. Karakteristik Responden Berdasarkan Jenis Kelamin dan Usia

\begin{tabular}{|c|c|c|}
\hline & Frekuensi & $\%$ \\
\hline \multicolumn{3}{|l|}{ Jenis kelamin } \\
\hline Laki-laki & 38 & 60.3 \\
\hline Perempuan & 25 & 39.7 \\
\hline Total & 63 & 100 \\
\hline \multicolumn{3}{|l|}{ Usia } \\
\hline 8 tahun & 9 & 14.3 \\
\hline 9 tahun & 44 & 69.8 \\
\hline 10 tahun & 10 & 15.9 \\
\hline Total & 63 & 100 \\
\hline
\end{tabular}

Tabel 1 menunjukkan bahwa $60.3 \%$ berjenis kelamin laki-laki dan $39.7 \%$ berjenis kelamin perempuan. Rentang usia dari 8-10 tahun, paling banyak $69.8 \%$ masuk dalam usia 9 tahun.

\section{B. Makanan Kariogenik}

Rerata makanan kariogenik yang dikonsumsi responden yaitu sebesar $7.9 \pm 2.7$ $\mathrm{x} /$ hari. Rerata tersebut jika dikategorikan maka hasilnya dapat dilihat pada tabel 2 .

Tabel 2. Jenis Makanan Kariogenik yang Dikonsumsi Responden

\begin{tabular}{ccc}
\hline $\begin{array}{c}\text { Jenis Makanan Kariogenik } \\
\text { yang dikonsumsi }\end{array}$ & Frekuensi & \% \\
\hline 3-6x sehari & 46 & 73.0 \\
2x sehari & 15 & 23.8 \\
1x sehari & 2 & 3.2 \\
Tidak pernah & 0 & 0 \\
\hline Total & $\mathbf{6 3}$ & $\mathbf{1 0 0}$ \\
\hline
\end{tabular}

Tabel 2 menunjukkan bahwa responden mengkonsumsi makanan kariogenik tertinggi sebanyak 3-6x sehari sebanyak 46 anak (73\%).

Jenis-jenis makan kariogenik tersaji pada tabel 3.

Tabel 3. Distribusi Frekuensi Pola Makan Makanan Kariogenik per Hari

\begin{tabular}{|c|c|c|c|c|c|c|c|c|c|c|}
\hline \multirow{4}{*}{$\begin{array}{c}\text { Jenis Makanan } \\
\text { Kariogenik }\end{array}$} & \multicolumn{6}{|c|}{ Frekuensi Pola Makan } & \multirow{3}{*}{\multicolumn{2}{|c|}{ Tidak Pernah }} & \multirow{3}{*}{\multicolumn{2}{|c|}{ Jumlah }} \\
\hline & \multirow{2}{*}{\multicolumn{2}{|c|}{$\mathbf{1 x}$}} & \multirow{2}{*}{\multicolumn{2}{|c|}{$\begin{array}{c}\text { Hari } \\
2 \mathrm{x}\end{array}$}} & & & & & & \\
\hline & & & & & \multicolumn{2}{|c|}{ 3x/Lebih } & & & & \\
\hline & $\mathrm{n}$ & $\%$ & $\mathrm{n}$ & $\%$ & $\mathrm{n}$ & $\%$ & $\mathrm{n}$ & $\%$ & $\mathrm{n}$ & $\%$ \\
\hline Permen & 29 & 46.0 & 23 & 36.5 & 9 & 14.3 & 0 & 0 & 61 & 99.5 \\
\hline Coklat & 26 & 41.3 & 11 & 17.4 & 8 & 12.7 & 0 & 0 & 45 & 71.4 \\
\hline Donat & 23 & 36.5 & 2 & 3.2 & 0 & 0 & 0 & 0 & 25 & 39.7 \\
\hline Kue Isi Selai & 18 & 28.5 & 5 & 7.9 & 0 & 0 & 0 & 0 & 23 & 36.4 \\
\hline Kue Lapis & 6 & 9.5 & 0 & 0 & 0 & 0 & 6 & 9.5 & 12 & 19.0 \\
\hline Dodol & 10 & 15.8 & 2 & 3.1 & 1 & 1.5 & 8 & 12.6 & 21 & 33.0 \\
\hline Gulali & 17 & 26.8 & 4 & 6.3 & 0 & 0 & 0 & 0 & 21 & 33.1 \\
\hline Arumanis & 11 & 17.4 & 0 & 0 & 0 & 0 & 15 & 23.8 & 26 & 41.2 \\
\hline $\begin{array}{l}\text { Makanan Ringan } \\
\text { (snack) }\end{array}$ & 29 & 46.0 & 24 & 38.1 & 0 & 0 & 0 & 0 & 53 & 84.1 \\
\hline
\end{tabular}

Tabel 3 menunjukkan hasil bahwa responden memiliki kebiasaan mengkonsumsi jenis makanan kariogenik setiap harinya. 


\section{Karies Gigi}

Hasil penelitian karies gigi dalam perhitungan DMF-T didapatkan rerata sebesar
$2.98 \pm 1.79$. Rerata tersebut dikategorikan maka hasilnya dapat dilihat pada tabel 4.

Tabel 4 . Distribusi Indeks DMF-T dan Frekuensi Karies Gigi

\begin{tabular}{cccc}
\hline $\begin{array}{c}\text { Status Karies Gigi } \\
\text { (DMF-T) }\end{array}$ & Frekuensi & $\%$ & DMF-T \\
\hline Sangat Rendah (0.0-1.1) & 26 & 41.2 & 0.5 \\
Rendah (1.2-2.6) & 22 & 34.9 & 2 \\
Sedang (2.7-4.4) & 15 & 23.8 & 4 \\
\hline
\end{tabular}

Tabel 4 menunjukkan bahwa status karies gigi responden berada pada level sangat rendah sampai sedang.

Tabel 5. Tindakan Responden Menggosok Gigi Setiap Hari

\begin{tabular}{lcc}
\hline \multicolumn{1}{c}{$\begin{array}{c}\text { Tindakan Menyikat Gigi } \\
\text { Setiap Hari }\end{array}$} & Frekuensi & $\%$ \\
\hline Ya & 63 & 100 \\
Kadang-Kadang & 0 & 0 \\
Tidak Pernah & 0 & 0 \\
\hline Total & $\mathbf{6 3}$ & $\mathbf{1 0 0}$ \\
\hline
\end{tabular}

Tabel 5 menunjukkan bahwa semua responden menggosok gigi setiap hari.

Tabel 6. Tindakan Responden Menyikat Gigi Sebelum Tidur

\begin{tabular}{lcc}
\hline \multicolumn{1}{c}{$\begin{array}{c}\text { Tindakan Menyikat Gigi } \\
\text { Sebelum Tidur }\end{array}$} & Frekuensi & \% \\
\hline Ya & 5 & 7.9 \\
Kadang-Kadang & 38 & 60.3 \\
Tidak Pernah & 20 & 31.7 \\
\hline Total & $\mathbf{6 3}$ & $\mathbf{1 0 0}$ \\
\hline
\end{tabular}

Tabel 6 menunjukkan hasil bahwa hanya sebagian responden yang menggosok gigi sebelum tidur.

\section{Status Gizi}

Status gizi responden dilihat berdasarkan IMT/U didapatkan median, hasilnya tersaji pada tabel 7.

Tabel 7. Karakteristik Status Gizi Pada Responden

\begin{tabular}{cccc}
\hline Karakteristik & Minimum & Maksimal & Median \\
Responden & 17.8 & 52.9 & 30.1 \\
\hline BB $(\mathrm{kg})$ & 125 & 148 & 136 \\
TB $(\mathrm{cm})$ & -4.24 & 2.96 & -0.36 \\
Z-score $(\mathrm{IMT} / \mathrm{U})$ & & & \\
\hline
\end{tabular}

Tabel 7 menunjukkan hasil bahwa Jika median Z-score tersebut dikategorikan, median Z-score responden sebesar $\quad-0.36$. maka hasilnya dapat dilihat pada tabel 8.

Tabel 8. Distribusi Frekuensi Status Gizi

\begin{tabular}{ccc}
\hline $\begin{array}{c}\text { Status Gizi } \\
\text { Responden }\end{array}$ & Frekuensi & $\%$ \\
\hline Sangat Kurus & & \\
Kurus & 10 & 15.8 \\
& 7 & 11.1 \\
\hline
\end{tabular}




\begin{tabular}{ccc}
\hline Normal & 25 & 39.6 \\
Gemuk & 16 & 25.3 \\
Obesitas & 5 & 8.2 \\
\hline Total & $\mathbf{6 3}$ & $\mathbf{1 0 0}$ \\
\hline
\end{tabular}

Tabel 8 didapatkan hasil bahwa $25.3 \%$ memiliki status gizi gemuk, $8.2 \%$ memiliki status gizi obesitas, $11.1 \%$ memliki status gizi kurus, dan $15.8 \%$ memiliki status gizi sangat kurus.

\section{E. Hubungan Antara Konsumsi Makanan Kariogenik dengan Karies Gigi}

Hasil uji hubungan antara konsumsi makanan kariogenik dengan karies gigi dapat dilihat pada gambar 1 .

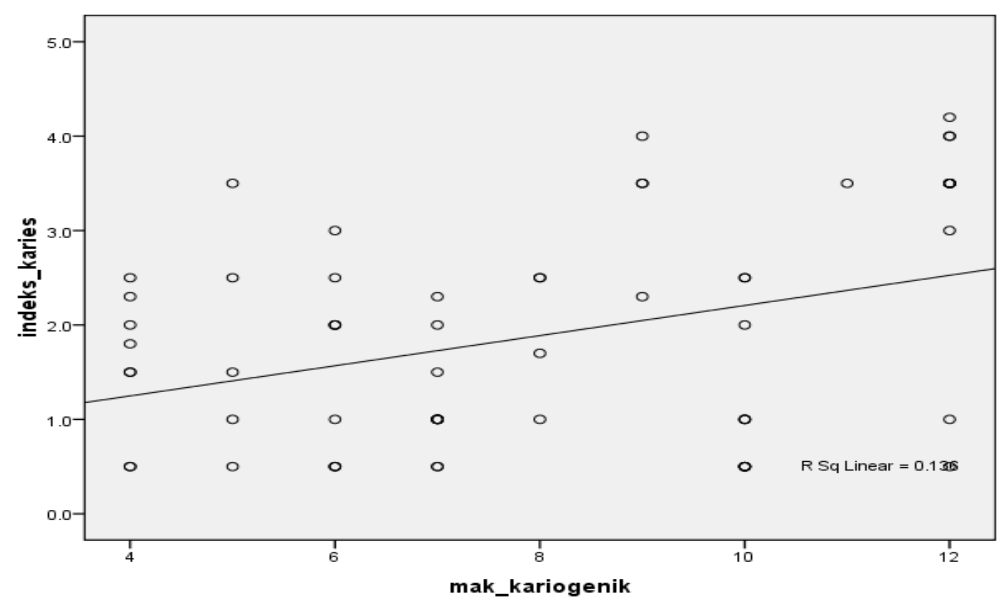

$\mathbf{p}=\mathbf{0 . 0 0 9}$

$\mathbf{r}=\mathbf{0 . 2 9 8}$

Gambar 1. Hubungan Antara Konsumsi Makanan Kariogenik dengan Karies Gigi

Berdasarkan gambar 1 menunjukkan hasil bahwa ada hubungan antara konsumsi makanan karieogenik dengan karies gigi $(\mathrm{p}=0.009 ; \mathrm{r}=0.298)$. Bila konsumsi makanan kariogenik meningkat, maka indeks karies giginya semakin tinggi.
F. Hubungan Antara Makanan Kariogenik dengan Status Gizi

Hasil uji hubungan antara makanan kariogenik dengan status gizi dapat dilihat pada gambar 2 .

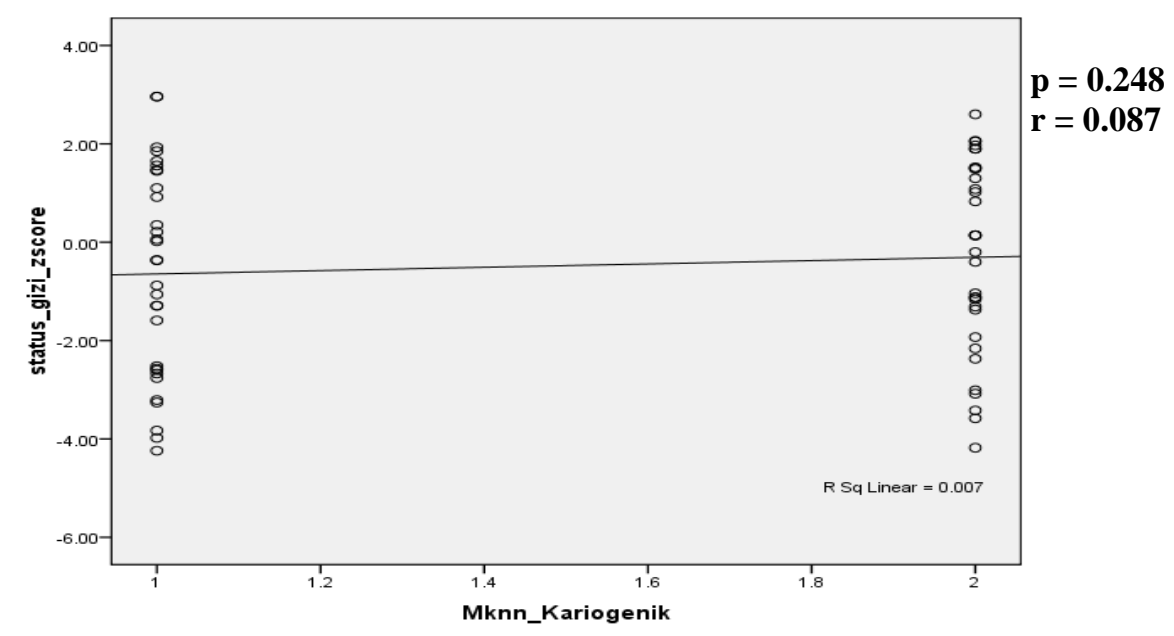

Gambar 2. Hubungan Antara Konsumsi Makanan Kariogenik dengan Status Gizi

Berdasarkan gambar 2 menunjukkan hasil bahwa tidak ada hubungan antara konsumsi makanan karieogenik dengan status gizi $(\mathrm{p}=0.248 ; \mathrm{r}=0.087)$ 


\section{G. Hubungan Antara Karies Gigi dengan Status Gizi}

Hasil uji hubungan antara karies gigi dengan status gizi dapat dilihat pada gambar 3 .

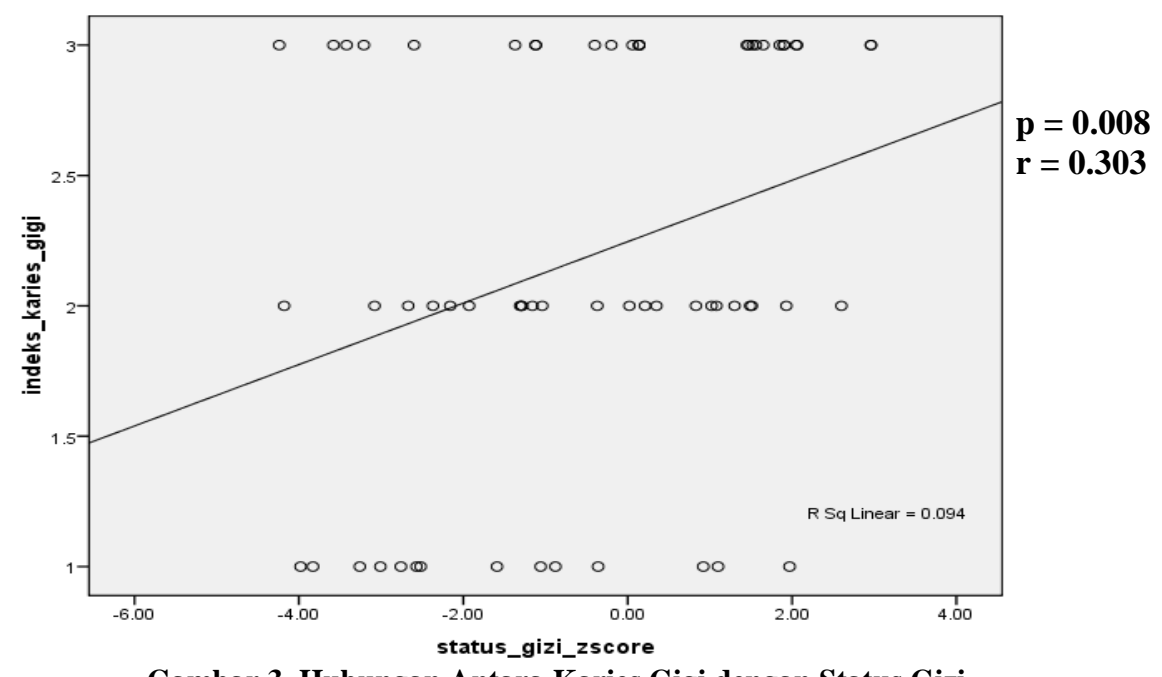

Gambar 3. Hubungan Antara Karies Gigi dengan Status Gizi

Berdasarkan gambar 3 menunjukkan hasil bahwa ada hubungan antara karies gigi dengan status gizi $(\mathrm{p}=0.008 ; \mathrm{r}=0.303)$. Semakin rendah indeks karies gigi pada responden, maka status gizinya akan semakin baik.

\section{PEMBAHASAN}

Hasil penelitian ini menunjukkan bahwa $23.8 \%$ responden mengalami karies gigi sedang dengan DMF-T sebesar 4. Hal ini dapat disebabkan karena responden tidak teratur menggosok gigi sebelum tidur. Hasil menunjukkan $60.3 \%$ responden kadang-kadang menggosok gigi sebelum tidur dan $31.7 \%$ tidak pernah menggosok gigi sebelum tidur. Gigi yang jarang dibersihkan akan menyebabkan sisa-sisa makanan yang tertinggal di rongga mulut mengendap didalam mulut dan akan menjadi plak. Hasil ini sama dengan penelitian yang dilakukan pada anak SD di Kawangkoan Utara tahun 2013 tentang karies gigi dan pola makan, yaitu diperoleh $60 \%$ anak mengalami karies gigi sedang dengan rata-rata DMF-T 3.86. Hal ini terjadi karena anak kurang menjaga kebersihan gigi dan mulut dan jarang menggosok gigi sebelum tidur. ${ }^{7}$

Berdasarkan hasil penelitian ini ditemukan adanya hubungan antara konsumsi makanan kariogenik dengan kejadian karies gigi. Hasil ini menunjukkan bahwa semakin tinggi anak yang mengkonsumsi makanan kariogenik, maka akan semakin tinggi indeks karies giginya. Jenis makanan yang sering dikonsumsi dapat mempengaruhi keparahan karies gigi. Salah satu makanan yang dapat menyebabkan karies gigi yaitu makanan yang banyak mengandung gula atau sukrosa. Sukrosa mempunyai kemampuan yang lebih efisien terhadap pertumbuhan mikroorganisme dan dimetabolisme dengan cepat untuk menghasilkan zat-zat asam. Makanan yang menempel pada permukaan gigi jika dibiarkan akan menghasilkan zat asam lebih banyak, sehingga mempertinggi risiko terkena karies gigi. Hasil ini sama dengan penelitian yang dilakukan pada anak SD 060935 Kota Medan tahun 2009, bahwa ada hubungan yang bermakna antara frekuensi makanan jajanan manis dengan karies gigi. Hasil penelitian tersebut menunjukkan anakanak yang frekuensi makanan jajanan manisnya tinggi memiliki tingkat keparahan karies gigi yang berat (74.2\%). (Barus, D. "Hubungan Kebiasaan Makan dan Pemeliharaan Kesehatan Gigi dengan Karies Gigi Pada Anak SD 060935 Jalan Pintu Air II Simpang Gudang Kota Medan”. 2008. Medan: Universitas Sumatera Utara.)

Jenis makanan kariogenik yang sering dikonsumsi menurut hasil penelitian, yaitu: permen; coklat; donat; kue isi selai; kue lapis; dodol; gulali; arumanis; makanan ringan (snack). Makanan-makanan tersebut bersifat manis dan menarik, sehingga anak menyukai makanan tersebut. Hal ini sama dengan penelitian yang dilakukan pada anak SDN 060935 Medan tahun 2008 tentang kesehatan gigi, bahwa sebagian besar anak sekolah sangat suka makanan yang manis, lunak, melekat (bersifat kariogenik) dan makanan yang bentuknya menarik. Meningkatnya konsumsi makanan-makanan tersebut yang kebanyakan 
mengandung gula, maka sering sulit bagi anak untuk menghindari konsumsi gula yang banyak. ${ }^{13}$

Makanan manis akan dinetralisir oleh air ludah setelah 20 menit, maka apabila setiap 20 menit sekali mengkonsumsi makanan manis akan mengakibatkan gigi lebih cepat rusak. Makanan manis lebih baik dimakan pada saat jam makan utama, seperti sarapan, makan siang, dan makan malam, karena pada waktu jam makan utama biasanya air ludah yang dihasilkan cukup banyak, sehingga dapat membantu membersihkan gula dan bakteri yang menempel pada gigi. ${ }^{12}$ Lamanya waktu yang dibutuhkan karies menjadi suatu lubang pada gigi sangat bervariasi, diperkirakan antara 6-48 bulan. Golongan anak sering terjadi serangan karies dalam kurun waktu 2-4 tahun sesudah erupsi gigi, yaitu biasanya pada anak usia 4-8 tahun. Gigi susu lebih mudah terserang karies daripada gigi tetap. Hal ini disebabkan karena enamel pada gigi tetap lebih banyak mengandung mineral, maka enamel pada gigi tetap semakin padat dibandingkan enamel pada gigi susu. Hal ini menjadi salah satu penyebab tingginya prevalensi karies pada anak-anak. (Wong, DL. dkk. Buku Ajar Keperawatan Pediatrik. 2008. Jakarta: EGC)

Akibat dari karies gigi tentunya menyebabkan rasa sakit pada responden, berupa rasa sakit spontan maupun karena adanya rangsang mekanisme dari makanan itu sendiri, yang pada akhirnya akan mengganggu fungsi pengunyahan. Terganggunya fungsi pengunyahan akan berpengaruh pada asupan zat gizi pada responden dan berpengaruh terhadap status gizinya. ${ }^{4}$

Berdasarkan dari hasil data penelitian ini didapatkan bahwa ada hubungan antara karies gigi dan status gizi. Hasil penelitian ini menjelaskan bahwa semakin rendah indeks karies gigi pada responden, maka status gizinya akan semakin baik. Kondisi status kesehatan gigi yang baik atau karies gigi yang rendah tentunya tidak menyulitkan proses pengunyahan makanan, karena gigi geligi memegang peranan penting, sehingga asupan zat-zat gizi berlangsung lebih baik, sesuai dengan kebutuhan tubuh. ${ }^{15}$ Hal ini berbeda dengan penelitian yang dilakukan pada SD Bawakaraeng tahun 2007, menunjukkan bahwa tidak ada hubungan antara karies gig dengan status gizinya. Hal ini disebabkan karena banyak faktor yang mempengaruhi pemenuhan kebutuhan gizi pada anak, disamping faktor ketersediaan makanan, juga faktor adanya penyakit yang dapat mempengaruhi asupan zat makanan pada anak. ${ }^{15}$

Karies gigi pada anak yang dapat menimbulkan gangguan dalam proses pencernaan dan kesulitan makan yang dapat menyebabkan gangguan pertumbuhan dan perkembangan. Hal tersebut serupa dengan penelitian pada anak SDN 091285 Medan tahun 2009 mengenai status gizi pada anak karies, bahwa akibat dari karies gigi adalah terganggunya fungsi pengunyahan (mastikasi). Anak dengan fungsi pengunyahan yang terganggu akan menghindari atau memilih makanan tertentu, sehingga asupan makanan akan berkurang dan akan berpengaruh terhadap status gizi anak tersebut. ${ }^{3}$ Sebagian responden menjelaskan bahwa ketika mengalami rasa sakit pada gigi, maka mereka akan memilih makanan dalam bentuk lunak. Hal ini disebabkan karena adanya gangguan terhadap fungsi gigi, bahkan beberapa anak ada yang mengalami penurunan nafsu makan. Menurut penelitian pada anak SD Aceh Besar tahun 2004 tentang keparahan karies dan status gizi, menjelaskan jika karies sudah meluas ke lapisan dentin, maka akan timbul rasa nyeri terutama jika terkena rangsangan dingin. Hal ini akan mengakibatkan terjadinya pemilihan jenis dan bentuk makanan yang akan dikonsumsi agar tidak menimbulkan rasa nyeri ketika makan. ${ }^{16}$

\section{DAFTAR PUSTAKA}

1. Jukes MCH, Drake LJ dan Bundy DAP. "School Healt, Nutrition and Education For All Levelling the Playing Field". CABI International. USA. 2008: p.3-29

2. Suwelo, IS. "Karies Gigi Pada Anak dengan Berbagai Faktor Etiologi". Jakarta: ECG, 1992

3. Damanik, Noverini E. "Gambaran Konsumsi Makanan Dan Status Gizi pada Anak Penderita Karies Gigi di SDN 091285 Panei Tongah Kecamatan Panei Tahun 2009”. FKM-USU. 2009:3

4. Sasiwi, R. "Hubungan Tingkat Keparahan Karies Gigi dengan Status Gizi Anak di Kabupaten Kendal". Universitas Diponegoro. Semarang. 2004. FKM-UNDIP

5. Departemen Kesehatan Republik Indonesia. Laporan Hasil Riset Kesehatan Dasar (RISKESDAS) Indonesia tahun 2013. Jakarta: Badan Penelitian dan Pengembangan Kesehatan.

6. Dinas Kesehatan Kabupaten Bojonegoro. Penjaringan Kesehatan Peserta Didik Tahun Ajaran 2012/2013. hal 1

7. Worotitjan. 2013. "Pengalaman Karies Gigi serta Pola Makan dan Minum Pada Anak SD Kecamatan Kawangkoan Utara". Manado. Jurnal e-Gigi(eG), Volume1,No1,Maret 2013, hlm.59-68

8. Srigupta, AA. Panduan Perawatan Gigi dan Mulut. 2004. Jakarta: Prestasi Pustaka

9. Barus, D. "Hubungan Kebiasaan Makan dan Pemeliharaan Kesehatan Gigi dengan Karies Gigi Pada Anak SD 060935 Jalan Pintu Air II Simpang 
Gudang Kota Medan”. 2008. Medan: Universitas Sumatera Utara

10. Albiner. Dumasari. 2008. "Hubungan Kebiasaan Makan dan Pemeliharaan Kesehatan Gigi dengan Karies Gigi Pada Anak SD 060935 Medan." Universitas Sumatera Utara

11. Nyoman, Supariasa. Penilaian Status Gizi. Jakarta :EGC, 2001

12. Ramadhan, AG. 2010. SerbaSerbi Kesehatan Gigi dan Mulut. Jakarta

13. Asmawati. 2007. "Analisis Hubungan Karies Gigi dan Status Gizi Anak SD Athirah, SDN 1 Bawakaraeng, SDN 3 Bangkala". Fakultas Kedokteran Gigi Universitas Hasanuddin. Makassar. Dentofasial, Vol.6, No.2, Oktober 2007: 78-84

14. Kusumawati, R. "Hubungan Tingkat Keparahan Karies Gigi dengan Status Gizi Anak SDN 01 Ciangsana Bogor". Fakultas Kedokteran dan Ilmu Kesehatan. Universitas Islam Negeri Syarif Hidayatullah. 2010. Jakarta

15. Junaidi. "Hubungan Keparahan Karies Gigi dengan Asupan Zat Gizi dan Status Gizi Anak SD Kec Lhoknga Kab Aceh Besar”. Program Pascasarjana Ilmu Kesehatan Masyarakat. Universitas Gadjah Mada. Yogyakarta: 2004

16. Wong, DL. dkk. Buku Ajar Keperawatan Pediatrik. Jakarta: EGC, 2008

17. Nugroho, AW. Santoso, Niko. Ilmu Gizi Menjadi Sangat Mudah. Jakarta: EGC; 2007. Pp.75;95; 100-1

18. Silaban, Sinta. "Prevalensi Karies Gigi Geraham Pertama Pada Anak Usia 8-10 tahun SD Kawangkoan". Kedokteran Gigi. Fakultas Kedokteran. Universitas Sam Ratulangi. 2013 